\title{
Assessing Exercise Performance during Exacerbations of Chronic Obstructive Pulmonary Disease: Work Smarter, not Harder!
}

\author{
Christian Osadnik $^{\mathrm{a}-\mathrm{c}}$ Barbara Vagagginid $^{\mathrm{d}}$ Pierluigi Paggiaro $^{\mathrm{d}}$ \\ ${ }^{a}$ Department of Physiotherapy, Monash University, ${ }^{\mathrm{b}}$ Institute for Breathing and Sleep, and ${ }^{\mathrm{C}}$ Monash Lung and \\ Sleep, Monash Health, Melbourne, Vic., Australia; ${ }^{d}$ Cardio-Thoracic and Vascular Department, University of \\ Pisa, Pisa, Italy
}

Hospitalizations due to acute exacerbation of chronic obstructive pulmonary disease (AECOPD) are characterized by prolonged bed rest, physical inactivity [1] and peripheral muscle wasting [2] that does not fully recover after discharge [3]. Given the risk of adverse health outcomes associated with these 'acquired' comorbidities (e.g. re-exacerbation, mortality) [4-6] and the role of physical activity in preventing these acute events $[5,6]$, it is unsurprising to observe strong interest in tailoring exercise prescription to individual needs as early as possible - even during the period of hospitalization. The period of inpatient hospitalization does, after all, offer benefits in terms of environment, staff and resources to conduct assessments of exercise performance.

Performing such testing during this time does not, however, come without challenge. Compared to the stable disease state, AECOPDs are associated with significantly worsened respiratory symptoms, enhanced airflow obstruction and systemic inflammation, and poorer exercise tolerance. These differences raise important questions that have not yet been answered regarding its appropriateness. For example, is it safe to perform (near maximal) exercise tests during an AECOPD? Can such tests be performed to satisfactory standards during the acute disease state? Should they be performed according to the same guidelines as during the stable state (e.g. are repeat tests necessary)? (c) 2015 S. Karger AG, Basel

0025-7931/15/0903-0189\$39.50/0
In this issue of Respiration, Johnson-Warrington et al. [7] report on a sub-analysis of data from a larger randomized controlled trial to explore incremental shuttle walk test (ISWT) performance near the time of hospital discharge. Their data provide interesting insight into some of these questions. From 52 eligible ISWT-naïve patients, $39(75 \%)$ patients with AECOPD were able and willing to complete repeat ISWTs despite this period of heightened symptom severity. The majority of patients performed exercise testing only a few days after hospital admission, and only 5 declined repeat testing due to severe symptoms. This information is, in its own right, valuable for the respiratory clinician as it demonstrates both the feasibility and acceptability of early mobilization in these acute patients.

Of primary interest, the magnitude of test-retest change in ISWT distance was variable (approx. 50\% improved and $50 \%$ did not), with repeat test performance potentially affected by a modest learning effect (mean difference $14 \mathrm{~m}$ ) and/or insufficient recovery from the initial test. Despite this variability, however, the authors were able to predict repeat ISWT distance with remarkable accuracy (multiple regression analysis explaining $98.8 \%$ of the variance) using easily obtainable clinical data. Predicted and actual distances walked did not significantly differ and demonstrated good agreement, although the data were understandably derived from predominantly low total

\section{KARGER 125}

E-Mail karger@karger.com

www.karger.com/res
Christian Osadnik

Department of Physiotherapy, Peninsula Campus, Monash University McMahons Road

Melbourne, VIC 3199 (Australia)

E-Mail christian.osadnik@monash.edu 
walk distance values $(<200 \mathrm{~m})$, potentially limiting the broader generalizability of the algorithm. Interestingly, despite this good agreement and the non-significant mean effect on endurance shuttle walk test level (a derivative of the ISWT), application of the predictive equation resulted in a difference of one endurance shuttle level on an individual basis in some participants. This may prove important when considering implementing the predictive equation into future research and clinical practice.

Why is this important? This is some of the first evidence of exercise test performance performed during the acute state, enabling evidence-based comparison to the extensive literature in stable COPD. It demonstrates similarities: that near-maximal exercise testing can be performed to satisfactory standards in AECOPD; and that learning effects, albeit small, exist. This is particularly relevant considering the importance of tailoring rehabilita- tion and physical activity programs immediately after AECOPD to reduce the risk of re-exacerbation [8]. However, it also demonstrates differences: the ability to accurately predict re-test performance, potentially mediated by the relatively small increase in repeat ISWT distance (and perhaps 'aided' by factors such as increased ventilatory limitation).

This research will hopefully raise interest in evaluating exercise performance in this AECOPD population and the factors related to the AECOPD that negatively affect exercise capacity (e.g. mechanical constraints vs. systemic inflammation vs. comorbidities) [9]. This is needed for future clinical practice and clinical research in order to optimize health outcomes through tailored interventions commenced early during this phase of deterioration. Smarter science clearly has the potential to help patients work less hard than previously thought necessary.

\section{References}

$>1$ Borges RC, Carvalho CR: Physical activity in daily life in Brazilian COPD patients during and after exacerbation. COPD 2012;9:596602.

-2 Spruit MA, Gosselink R, Troosters T, Kasran A, Gayan-Ramirez G, Bogaerts P, et al: Muscle force during an acute exacerbation in hospitalised patients with COPD and its relationship with CXCL8 and IGF-I. Thorax 2003;58: 752-756.

$>3$ Pitta F, Troosters T, Probst VS, Spruit MA, Decramer M, Gosselink R: Physical activity and hospitalization for exacerbation of COPD. Chest 2006;129:536-544.
4 Garcia-Aymerich J, Farrero E, Felez MA, Izquierdo J, Marrades RM, Anto JM, et al: Risk factors of readmission to hospital for a COPD exacerbation: a prospective study. Thorax 2003;58:100-105.

5 Garcia-Aymerich J, Lange P, Benet M, Schnohr P, Anto JM: Regular physical activity reduces hospital admission and mortality in chronic obstructive pulmonary disease: a population based cohort study. Thorax 2006; 61:772-778.

-6 Moy ML, Teylan M, Weston NA, Gagnon DR, Garshick E: Daily step count predicts acute exacerbations in a US cohort with COPD. PLoS One 2013;8:e60400.
7 Johnson-Warrington V, Mitchell KE, Singh SJ: Is a practice incremental shuttle walk test needed for patients with chronic obstructive pulmonary disease admitted to hospital for an acute exacerbation? Respiration 2015;90: 206-210.

8 Puhan MA, Gimeno-Santos E, Scharplatz M, Troosters T, Walters EH, Steurer J: Pulmonary rehabilitation following exacerbations of chronic obstructive pulmonary disease. Cochrane Database Syst Rev 2011:CD005305.

-9 Barnes PJ, Celli BR: Systemic manifestations and comorbidities of COPD. Eur Respir J 2009;33:1165-1185. 